\title{
Familia de origen del orientador en la praxis de la orientación familiar ${ }^{1}$ María Campo-Redondo ${ }^{2}$, Flor María Roquett de Moreau ${ }^{3}$ Maracaibo, Venezuela
}

\begin{abstract}
El estudio tuvo como objetivo proponer una aproximación teórica de la incidencia del trabajo con la familia de origen del orientador en la praxis de la orientación familiar. La investigación se ubica en el enfoque epistemológico Introspectivo-vivencial y se apoya en la metodología de la teoría fundamentada. Se utilizó un procedimiento mixto de recolección de datos de tipo vivencial y documental, los cuales conformaron el muestreo teórico de la investigación. Los resultados develaron que el trabajo con la familia de origen, es una vivencia transformadora, que genera una nueva disposición a percibir y comprender la propia historia familiar, siendo considerado una vía para el encuentro y revisión de situaciones vividas en familia; así como, un recurso de formación del orientador familiar, que facilita el desarrollo de competencias personales, la búsqueda de la consciencia de sí mismo y seguridad en el desempeño profesional, desde el control y dirección del proceso de asesoramiento; lo que lleva a la afirmación que el trabajo con la familia de origen incide en el fortalecimiento de la práctica de la orientación familiar.
\end{abstract}

Palabras clave: Familia de origen, orientación familiar, vivencia transformadora y recurso de formación.

The research's objective was to propose a theoretical approach that would explain the incidence of the work with the counselor's family of origin in the family counseling practice. Epistemologically, this research is founded by a introspective-experiential approach, and methodologically supported by grounded theory. A mixed data collecting instrument of experiential and documental type was used. Results showed that the family of origin work, is a transforming experience, that generates a new disposition to perceive and understand the counselor's own family of origin, being considered a way to find and review lived situations in family, as well as, a family counselor's formation resource that facilitates development of personal skills, selfconsciousness search and confidence in the professional performance, from the control and direction of the counseling process which leads to the affirmation that the work with the family of origin influences in the strengthening of the family counseling practice.

Key Words: Family of origin, family counseling, transforming experience and formation resource.

\section{English Title: Counselor's family of origin in family counseling practice}

\section{Cita bibliográfica / Reference citation:}

Campo-Redondo, M. y Roquett de Moreau, F.M. (2017). Familia de origen del orientador en la praxis de la orientación familiar. Clínica e Investigación Relacional, 11 (1): 145-164. [ISSN 1988-2939]

[Recuperado de www.ceir.info ] DOI: 10.21110/19882939.2017.110109

\footnotetext{
${ }^{1}$ Este trabajo (inédito), forma parte de la Tesis Doctoral de Flor Roquett, tutorada por María Campo-Redondo, titulada "FAMILIA DE ORIGEN DEL ORIENTADOR EN LA PRAXIS DE LA ORIENTACIÓN FAMILIAR". Universidad del Zulia. Facultad de Humanidades y Educación. División de Estudios para Graduados. Programa de Doctorado en Ciencias Humanas. Maracaibo, Venezuela, 2016.

${ }^{2}$ Psicólogo-psicoterapeuta. Doctora en Ciencias Humanas. Profesora titular de la Universidad del Zulia (LUZ) y Universidad Rafael Urdaneta (URU). Corresponsal de la revista CelR en Maracaibo, Venezuela. Email: marisucampo@yahoo.com

3 Orientadora y Doctora en Ciencias Humanas. Profesora del Centro de Investigaciones Psiquiátricas, Psicológica y Sexológicas de Venezuela (CIPPSV), sede Zulia. Maracaibo, Venezuela. Email: Roquett_Flor@msn.com
} 


\section{INTRODUCCIÓN}

La familia en un sistema complejo en evolución constante y de larga duración, y en consecuencia el impacto que la vida familiar tiene en sus miembros, es también complejo y duradero. Así, el desarrollo del ser humano está condicionado al entorno social, el niño se humaniza en lo social, en contacto e interacción con los demás, en contacto con los próximos y, particularmente, con los de la familia de origen, que es donde el individuo establece los primeros vínculos afectivos de los que en gran medida dependerá el desarrollo adulto, tanto afectivo como cognitivo y social (Mahoney, 1991 y Ainsworth, 1987). La familia, es pues, el núcleo de esa red social que tanto el niño como el adulto necesitan para su propio desarrollo personal; a la vez que marca en la persona, actitudes psicosociales de un modo definitivo.

Por otro lado, a medida que se avanza en la vida, cada cual constituye dentro de sí una imagen de su propia familia, que no está siempre regida por un criterio de realidad, sino por poderosos determinantes psicológicos; esta familia internalizada, de manera inconsciente, se convierte en un modelo personal, que influye en la percepción y comprensión de la dinámica relacional en que la persona se ve involucrada.

Desde esta perspectiva, el legado de la familia va más allá de la adaptación al entorno, su influencia perdura en el tiempo y se transmite a otras generaciones; especial atención merecen los conflictos sin resolver, que en mayor o menor grado pueden formar parte del legado familiar y convertirse en proceso que se repiten y que deterioran la vida familiar en el presente; así como llegar a considerarlo como hechos válidos en la dinámica familiar.

De acuerdo a lo expuesto, la tarea de conocer la propia historia familiar permite hacer consciente ese legado, llenando lagunas, aclarando puntos confusos, develando secretos, complementando puntos de vista, conociendo las causas muchas decisiones, afectos y conductas, activando recursos. Así como, la posibilidad de distanciamientos emocionales y la reconciliación con el pasado.

Ahora bien, como todo ser humano, el orientador familiar, nace en una familia, que le ha dejado huellas imborrables, las cuales forman parte de su identidad personal. Cabe destacar, que el primer recurso del orientador es su persona, lo que implica el reconocimiento de su historia familiar, como requisito para su desempeño profesional. Además, desde una perspectiva de la ética profesional y personal, todo sujeto que trabaja en el área de la orientación familiar, adquiere la responsabilidad de conocer acerca de sí mismo, su subjetividad y su familia extendida, a fin de asegurarse que su funcionamiento y subjetividad, no interfieran negativamente en la efectividad del proceso de ayuda; lo cual permite reafirmar, que el trabajo personal debe ser parte de su formación y desarrollo profesional, por ser su persona su principal herramienta en el proceso de ayuda.

Igualmente, conviene destacar, que la práctica de la orientación familiar, parte de una relación interpersonal entre el profesional y la familia atendida, que según Henry, Sims y Spray (1973) es a la vez el objeto y la mecánica de la intervención, sin que tenga mayor peso la orientación teórica utilizada.

Ahora bien, el trabajo con la historia familiar del orientador/terapeuta, ha sido considerado una estrategia de aprendizaje personal, que implica una opción de realizar una relectura de las 
vivencias familiares, desde la autobservación, permitiendo el reconocimiento de las emociones involucradas en las experiencias vividas y la posibilidad de la toma de consciencia de reacciones inconscientes antes situaciones similares. Igualmente, permite identificar las posiciones asumidas y los mandatos asignados por el grupo familiar.

Además, diversos estudios han permitido reconocer la efectividad del trabajo con la familia de origen, muy especialmente en la formación del terapeuta u profesionales de orientación familiar; al respecto, Kerr y Bowen (1988) y Kerr (1984) señalan que la aproximación a la propia familia de origen constituye una alternativa para fomentar el crecimiento personal; por cuanto consideran, dichos autores, que el crecimiento personal es homólogo al proceso de diferenciación del sí mismo; siendo el postulado que guía y norma todo esfuerzo hacia un mejor nivel de diferenciación, en relación con la propia familia de origen, el siguiente: "Todas las personas tienen, en referencia a su propia familia parental, algún grado de apego aún no resuelto" Kerr (1984).

Por su parte, González (2006), señala que el trabajo con la familia de origen contribuye al aumento de la autoafirmación, mejora la confianza en sí mismo y la capacidad de introspección; incrementando la tendencia a la reflexión, la sensibilidad y la automanifestación; aportando profundidad, sutileza, apreciación y comprensión de los demás; a las vez que contribuye al aumento de la tolerancia, comprensión y la paciencia. Además confirma, dicho autor, que vivir la experiencia de un ejercicio de reflexión sobre la propia familia de origen, puede ayudar a apreciar y darle más valor a lo que cuentan las familias con las que se trabaje.

Otra contribución del trabajo con la familia de origen, tiene que ver con el aporte que esta experiencia tiene en la estabilidad emocional del participante, ya que facilita la expresión y reflexión de su emotividad. En relación a lo señalado, Bowen y Kerr (1988) refieren, que disminuir la intensidad de las reacciones emocionales está relacionado con conocer la propia historia familiar, por cuanto mientras más comprenda un individuo a su familia, más fácil le será reducir la reactividad y subjetividad que lo llevó a la reacción emocional.

Cabe exponer, la importancia de promover el desarrollo personal del orientador, tanto en su formación, como a la largo de su desempeño profesional, lo cual ha sido considerada un imperativo ético y requisito de eficiencia en todas las escuelas de orientación familiar; según Henry, citado por Guy (1995), todo proceso de formación, implica algo más que cierto grado de socialización y aprendizaje conceptual, señalando dicho autor, la importancia del reconocimiento, en el estudiante y en el profesional, de los conflictos, traumas y obsesiones no resueltas en su grupo familiar; lo cual ha conllevado a la utilización de varios medios que facilite dicho proceso.

Igualmente, Salem (1990) refiere que un conocimiento de sí mismo tan profundo como sea posible es, no sólo deseable, sino también indispensable; afirmando dicho autor, que los profesionales que hacen este tipo de trabajo sobre sí mismos y desde las historias de sus familias de origen son más eficientes en sus intervenciones. De hecho, se ha podido determinar que a partir del autoconocimiento personal y aceptación de las vivencias familiares; así como la reflexión respecto a su propia familia de origen, contribuye a la efectividad del proceso relacional del asesoramiento familiar.

Por otra parte, Bowen (1986) refiere que los problemas presentados por las familias atendidas son generalmente, los mismos problemas que existen en la propia familia del orientador familiar; además, este autor resalta, la importancia de realizar una exploración y un entendimiento 
de la dinámica, patrones y relaciones de la propia familia del orientador, para lograr un trabajo efectivo, en las familias atendidas. Desde esta perspectiva, trabajar con familias, sin explorar las propias vivencias familiares, puede conducir a centrarse más en las propias necesidades o carencias que en las familias atendidas.

Partiendo del reconocimiento de la importancia del trabajo con la historia de la familia de origen del orientador familiar en su práctica profesional, la investigación estuvo dirigida a proponer una aproximación teórica que explique la incidencia del trabajo con la familia de origen del orientador en la práctica de la orientación familiar.

\section{ESTRATEGIA METODOLÓGICA}

La investigación fue desarrollada a partir del enfoque epistemológico Introspectivo-vivencial, sustentado en una metodología interpretativa y subjetiva; desarrollada a través un procedimiento mixto de recolección de datos (vivencial y documental). Con respecto al análisis de los datos, se utilizó el procedimiento de la teoría fundamentada, la cual es definida por Strauss y Corbin (2002), como un enfoque de la investigación cualitativa que aplica un conjunto de procedimientos para el desarrollo inductivo de una teoría acerca del fenómeno estudiado; siendo su objetivo principal el desarrollo de una explicación descriptiva del fenómeno en estudio que permita identificar los constructos más relevantes del mismo, o categorías en términos de la teoría fundamentada; así como hacer visible el sistema de relaciones internas dadas en el fenómeno, de acuerdo al contexto y los procesos que le caracterizan. En consecuencia, el procedimiento de la teoría fundamentada permite el diseño de una teoría explicativa acerca del fenómeno más allá de lo puramente descriptivo del mismo (Becker, 1970).La estrategia metodológica se desarrolló a través de tres fases:

Fase Vivencial: Esta fase tuvo como objetivo recolectar los datos primarios de la investigación, los cuales permitieron comprender el significado que tiene para el orientador el trabajo con su familia de origen. Los datos señalados fueron suministrados por los cursantes del tercer semestre de la Maestría de Orientación de Educación para Padres, del Centro de Investigaciones Psiquiátricas, Psicológica y Sexológicas de Venezuela (CIPPSV), sede Zulia, en Maracaibo, Venezuela, que participaron en el Seminario I (introducci, que tuvo como objetivo develar la importancia del Genograma Familiar en el proceso de asesoramiento familiar.Los informantes realizaron su genograma familiar, el cual consiste en una representación gráfica del sistema familiar, que incluye tres o más generaciones, proporcionando una mirada global de la complejidad de las estructuras y relaciones familiares vividas; constituyéndose en una fuente de hipótesis explicativas que considera el contexto relacional y la evolución de la red familiar a través del tiempo; también es utilizado como una herramienta de investigación que permite adentrarse en la historia de una familia y en los procesos emocionales que allí ocurren, ya sea con un fin clínico o con una orientación que apunte al mayor conocimiento de sí mismo.

Esta experiencia vivencial permitió el trabajo con la historia de la familia de origen de los participantes, que luego debieron presentar informe escrito en digital de la experiencia vivida en dicho trabajo. De los datos presentados, en dichos informes, partió el muestro teórico o muestra basada en constructos teóricos relevantes. Cabe señalar, que en la teoría fundamentada la 
recogida de los datos va configurando el tamaño de la muestra final; siendo está determinada por el desarrollo de las categorías identificadas y la teoría emergente. En la investigación la muestra teórica quedó conformada por los trabajos escritos de ocho participantes que realizaron y culminaron el referido seminario; siendo esta selección intencional, fundamentada en la amplitud y relevancia del informe escrito presentado por los informantes claves. Es así, que los informes elaborados por los participantes del seminario, permitieron obtener los datos requeridos para el análisis e interpretación de la información, con el fin de alcanzar el objetivo planteado.

Fase Documental: El propósito de esta fase fue realizar una revisión documental en publicaciones científicas en búsqueda de documentos teóricos relacionados al trabajo con la familia de origen en la práctica de la orientación familiar. En relación a dicho proceso de revisión, Strauss y Corbin (2002, pág. 57 y 232), explican que las fuentes bibliográficas y las publicaciones de investigación incluyen materiales descriptivos relacionados con eventos, acciones, ambientes y perspectivas de los autores, los cuales pueden ser utilizados como fuentes secundarias de datos en la investigación, y analizarse usando los métodos de la teoría fundamentada.

Esta fase se inicia con la revisión de modelos teóricos con marcadas diferencias epistemológicas, siendo seleccionados los siguientes: el psicoanálisis, el cognitivo conductual y el sistémico. Por otro lado, se trabajó con enfoques teóricos más específicos, tales como, la transmisión intergeneracional, el proceso de diferenciación del sí mismo, la teoría del apego y la intersubjetividad. Igualmente se realizó una revisión de estudios relacionados con experiencias vivenciales y trabajos de investigación sobre el hecho estudiado. Dicha revisión documental conforman los datos secundarios que complementan el muestreo teórico.

Fase de Integración y Teorización: La fase tuvo como objetivo: en un primer momento, la construcción un esquema teórico explicativo del trabajo con la familia de origen del orientador en la práctica de la orientación familiar; para en un segundo momento, elaborar un relato sistemático, lógico e integrado de la aproximación teórica del hecho estudiado.

Esta fase se sustenta en lo propuesto por Strauss y Corbin (2002), quienes declaran que teorizar es un trabajo que implica no solo concebir o intuir ideas (conceptos), sino formularlos en un esquema lógico, sistemático y explicativo. De igual manera, se fundamenta en lo señalado por Hage (1972) quien afirma que para explicar o predecir se necesita una declaración teórica que parta de una conexión entre dos o más conceptos; es decir, debe ser más que un conjunto de hallazgos, pues debe ofrecer explicaciones sobre el fenómeno estudiado.

\section{RESULTADOS}

Los resultados develados en la fase vivencial, a través del análisis de las narraciones de los informantes, fueron integrados una estructura conformada, por una categoría central, cuatro subcategorías y ocho dimensiones, las cuales se visualizan en la figura No. 1 ; igualmente, dicha categoría, subcategorías y dimensiones fueron definidas y presentadas con los textos de narraciones aportadas por los informantes, los cuales se presentan el cuadro No. 1. 


\section{Figura $\mathrm{N}^{\circ} 1$}

Visualización de la Interacción entre categoría central, subcategorías y dimensiones del significado del trabajo con la familia de origen

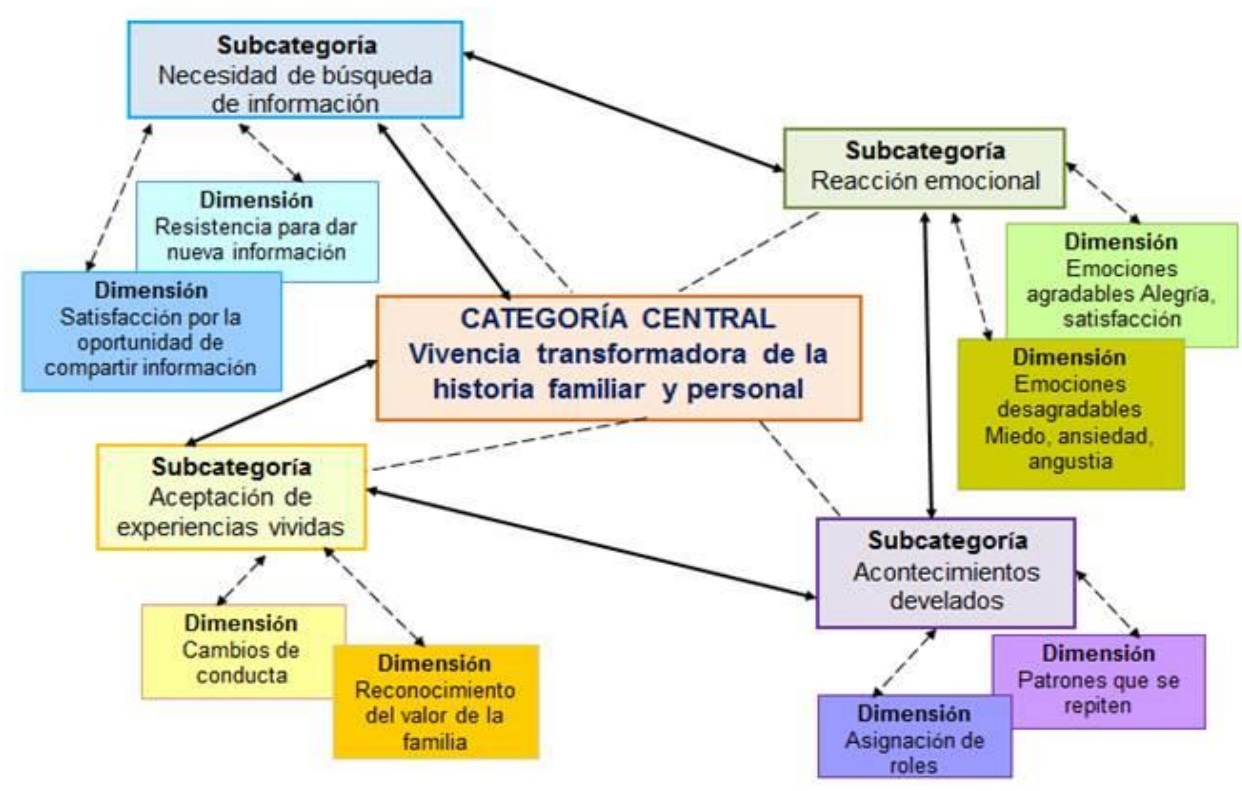

\section{Cuadro $\mathrm{N}^{\circ} 1$}

Descripción de la Categoría Central, Subcategorías y Dimensiones, junto con sus definiciones y ejemplos textuales de las narraciones de los informantes.

\begin{tabular}{|c|c|c|}
\hline Categoría Central & Definición & Textos de las narraciones de los informantes \\
\hline $\begin{array}{l}\text { Vivencia transformadora } \\
\text { de la historia familiar y } \\
\text { personal }\end{array}$ & $\begin{array}{l}\text { Es una experiencia que } \\
\text { genera una nueva } \\
\text { disposición a percibir y } \\
\text { comprender su historia } \\
\text { familiar y personal. }\end{array}$ & $\begin{array}{l}\text {......ahora puedo apreciar que todas esa experiencias } \\
\text { que me han marcado durante mi vida la puedo } \\
\text { recordar como una enseñanza y olvidando el dolor } \\
\text { que causaron en ese momento me ha permitido } \\
\text { fortalecerme como persona para poder alcanzar las } \\
\text { metas propuestas en la vida. } \\
\text {......he tomado consciencia de las situaciones } \\
\text { pasadas que han afectado mi relación familiar. Ahora } \\
\text { estoy consciente de lo que ha estado pasando en mi } \\
\text { familia, que solo son programas que han venido } \\
\text { dándose de generación en generación y debo cortar } \\
\text { con eso. Ahora sé que lo que desconozco se puede } \\
\text { repetir y lo que conozco yo decido repetir o no. } \\
\text {......del temor a la comprensión fue el cambio que } \\
\text { hice con este trabajo. } \\
\text {......en este trabajo descubrí que a pesar de las malas } \\
\text { experiencias, también tuvimos bellas experiencias. } \\
\text { Que muchas cosas dependen de nuestra percepción } \\
\text { de la situación, que no debo enfocarme en lo que no } \\
\text { tuve, sino más bien en las cosas buenas de mis } \\
\text { padres, que si hago un balance fueron muchas, que }\end{array}$ \\
\hline
\end{tabular}

\section{CelR Vol. 11 (1) - Febrero 2017 ISSN 1988-2939 - www.ceir.info}

@ Derechos reservados/Copyright de Clínica e investigación Relacional y los autores. Prohibida la reproducción total o parcial sin autorización expresa. Este material es para uso científico y profesional exclusivamente y puede contener información clínica sensible. Los editores no se responsabilizan de los contenidos de los autores. Dirigir las consultas sobre derechos y autorizaciones a ceir@psicoterapiarelacional.es 


\begin{tabular}{|c|c|c|}
\hline & & $\begin{array}{l}\text { no tengo que arrastrar con mis debilidades toda la } \\
\text { vida, a cambio debo enfocarme en lo bueno que } \\
\text { puedo dar a otros. } \\
\text {...este trabajo me gustó porque crea mucho insight, } \\
\text { ayuda colocarse metas, a reflexionar de cómo están } \\
\text { siendo mis conductas y por qué debo mejorarlas, } \\
\text { entender que somos como fuimos criados y las } \\
\text { experiencias vividas, más nuestro procesamiento o } \\
\text { creencias de esas experiencias. } \\
\text {.....después de trabajar con mi familia puedo decir } \\
\text { que la aceptación de mi historia es primordial, ya que } \\
\text { mi pasado y las cosas que viví en mi hogar, ya no las } \\
\text { puedo cambiar y si sucedieron fue porque así está } \\
\text { dispuesto a ser, como mi propio padre dice cuando le } \\
\text { hemos reprochado el porqué de sus acciones, nos } \\
\text { dijo "nadie da lio que no tiene" palabras que se } \\
\text { grabaron en mi mente y que me llevan a pensar que } \\
\text { al igual que mis hermanos y yo, ellos también } \\
\text { estaban madurando y lo hicieron de la forma que } \\
\text { conocían y dieron lo que tenían en ese momento. } \\
\text {....realmente creo que después de este trabajo } \\
\text { inevitablemente en mi vida se producirán grandes } \\
\text { cambios. } \\
\text {.....fue emocionante trabajar con la historia de mi } \\
\text { familia, no solo para mí, sino para toda la familia, por } \\
\text { el interés que despertó en cada uno de ellos saber } \\
\text { cuál es el origen y escuchar de nuevo a mi mamá } \\
\text { hablar de los familiares fallecidos, pensé que era un } \\
\text { trabajo difícil, pero a medida que lo iba haciendo me } \\
\text { di cuenta que era fascinante. }\end{array}$ \\
\hline Subcategoría & Definición & Textos de las narraciones de los informantes \\
\hline Búsqueda de información & $\begin{array}{l}\text { Necesidad de encuentro } \\
\text { familiar con el objetivo } \\
\text { de obtener nueva } \\
\text { información. }\end{array}$ & $\begin{array}{l}\text {....cuando comencé el trabajo se me presentó una } \\
\text { dificultad, y era que poseía muy poca información de } \\
\text { mi familia de origen, por lo que tuve que empezar a } \\
\text { recopilar información, llamar por teléfono a mis } \\
\text { hermanos, visitar a mi mamá biológica, pero una } \\
\text { visita un tanto diferente, en donde salieron a relucir } \\
\text { datos que desconocía, pero que a la vez sentí que le } \\
\text { quitaron cargas a mi madre, luego de unas pequeñas } \\
\text { lágrimas le pude observar una mirada más brillante y } \\
\text { su corazón se llenó de paz, según así ella misma me } \\
\text { lo manifestó. } \\
\text {.......tuve que viajar al Mojan, realicé gran cantidad de } \\
\text { llamadas y busqué en fuentes escritas (actas de } \\
\text { defunción, partidas de nacimientos, cédulas de } \\
\text { identidad) para obtener y completar los datos. } \\
\text {.......para obtener información tuve que reunirme con } \\
\text { mis padres, me sentí muy bien compartiendo con } \\
\text { ellos, les pregunté a ellos sobre sus padres y } \\
\text { hermanos, mi mamá me podía dar más información }\end{array}$ \\
\hline
\end{tabular}

\section{CelR Vol. 11 (1) - Febrero 2017 ISSN 1988-2939-www.ceir.info}

@ Derechos reservados/Copyright de Clínica e investigación Relacional y los autores. Prohibida la reproducción total o parcial sin autorización expresa. Este material es para uso científico y profesional exclusivamente y puede contener información clínica sensible. Los editores no se responsabilizan de los contenidos de los autores. Dirigir las consultas sobre derechos y autorizaciones a ceir@psicoterapiarelacional.es 


\begin{tabular}{|c|c|c|}
\hline & & $\begin{array}{l}\text { ya que la sabia y se acordaba muy bien, pero mi papá } \\
\text { se le dificultó más porque no recordaba muchas } \\
\text { cosas aunque poco a poco fue recordaba, cada vez } \\
\text { que recordaba algo me buscaba o llamaba para } \\
\text { darme la información. }\end{array}$ \\
\hline Dimensiones & Definición & Textos de las narraciones de los informantes \\
\hline $\begin{array}{l}\text { Resistencia para dar } \\
\text { nueva información }\end{array}$ & $\begin{array}{l}\text { Negación a proporcionar } \\
\text { información que se } \\
\text { conoce. }\end{array}$ & $\begin{array}{l}\text {.....mi madre no mostró interés en darme la } \\
\text { información que necesitaba, tuve que pedirle que por } \\
\text { favor me ofreciera datos y hechos reales e } \\
\text { importantes que debía obtener, a lo cual luego } \\
\text { accedió. } \\
\text {.....muchas veces sentí que ya no me querían dar más } \\
\text { información, a pesar que sabían más de lo que } \\
\text { decían, eso fue frustrante. } \\
\text {.....es importante acotar que a mis tías les incomodó } \\
\text { que les preguntara tanto al igual que a mi mamá. }\end{array}$ \\
\hline $\begin{array}{l}\text { Satisfacción por la } \\
\text { oportunidad de compartir } \\
\text { información }\end{array}$ & $\begin{array}{l}\text { Estado afectivo } \\
\text { agradable como } \\
\text { resultado de compartir } \\
\text { información que conoce. }\end{array}$ & $\begin{array}{l}\text {.....nos reunimos, fue muy satisfactorio, pude ver a } \\
\text { mis padres felices con sus recuerdos e historias de } \\
\text { cuando fueron pequeños y algunas experiencias } \\
\text { significativas de ellos. } \\
\text {......siento que fue un aspecto muy importante ver } \\
\text { sonreír a mis padres con historias de su infancia y mis } \\
\text { hermanas acordándose de sus travesuras de } \\
\text { pequeñas. } \\
\text {.....como familia nos unimos más, pudimos destacar } \\
\text { nuestras fortalezas, también señalamos nuestras } \\
\text { debilidades, fue muy valioso poder contar nuestras } \\
\text { historias estando todos presentes. }\end{array}$ \\
\hline Subcategoría & Definición & Textos de las narraciones de los informantes \\
\hline Reacción emocional & $\begin{array}{l}\text { Respuesta fisiológica y } \\
\text { motora, de poca } \\
\text { duración y puede ser } \\
\text { agradable o } \\
\text { desagradable. }\end{array}$ & $\begin{array}{l}\text {.....esto fue una vivencia de sentimientos } \\
\text { encontrados de rabia, frustración, no séqué decir. } \\
\text {.....no podía entender pero sentía mucha emoción, } \\
\text { no se si era miedo o era inquietud por tener que saber } \\
\text { la historia de mi familia, después que comencé se me } \\
\text { pasó. } \\
\text {.....esto fue como pasar de una emoción a otra, pero } \\
\text { muy rápido, la verdad fue que me gustó. } \\
\text {......realizar el trabajo fue emocionante, no solo para } \\
\text { mí, sino para toda la familia. }\end{array}$ \\
\hline Dimensiones & Definición & Textos de las narraciones de los informantes \\
\hline $\begin{array}{l}\text { Emociones agradables, } \\
\text { alegría, satisfacción }\end{array}$ & $\begin{array}{l}\text { Reacción que se } \\
\text { manifiesta en } \\
\text { sensaciones agradables. }\end{array}$ & $\begin{array}{l}\text {.....cuando viví la experiencia de trabajar con mi } \\
\text { familia me sentí emocionalmente feliz y alegre por } \\
\text { vivir esta experiencia. } \\
\text {....el trabajo con mi familia fue una experiencia } \\
\text { agradable, me gustó y resultó ser de mucho interés } \\
\text { para mí, sentí mucha satisfacción por conocer la } \\
\text { historia de mi familia. }\end{array}$ \\
\hline $\begin{array}{l}\text { Emociones } \\
\text { desagradables, miedo, } \\
\text { ansiedad, angustia }\end{array}$ & $\begin{array}{l}\text { Reacción que se } \\
\text { manifiesta en }\end{array}$ & $\begin{array}{l}\text {....sentí miedo al recordar cosas de mi pasado y } \\
\text { miedo de conocer situaciones por las cuales tuvo que } \\
\text { pasar mi familia. }\end{array}$ \\
\hline
\end{tabular}




\begin{tabular}{|c|c|c|}
\hline & $\begin{array}{l}\text { sensaciones } \\
\text { desagradables. }\end{array}$ & $\begin{array}{l}\text {......durante la construcción de mi genograma } \\
\text { familiar sentí frustración y algo enojada, pues me } \\
\text { sentí ignorante al desconocer gran parte de los datos } \\
\text { que forma la historia de mi familia. } \\
\text {......en algunas ocasiones sentí cierto temor y } \\
\text { curiosidad proveniente de mis entrevistados, lo que } \\
\text { me hacía sentirme verdaderamente incomoda. } \\
\text {......esto fue una experiencia de sentimientos } \\
\text { encontrados, de rabia y frustración. } \\
\text {.....al comenzar sentí mucha ansiedad ya que no tenía } \\
\text { toda la información y la tía que me la podía dar estaba } \\
\text { de viaje. }\end{array}$ \\
\hline Subcategoría & Definición & Textos de las narraciones de los informantes \\
\hline $\begin{array}{l}\text { Acontecimientos } \\
\text { develados }\end{array}$ & $\begin{array}{l}\text { Situaciones que se } \\
\text { confirman o se } \\
\text { descubren en la familia. }\end{array}$ & $\begin{array}{l}\text {....poco a poco mediante la entrevista que tuvimos se } \\
\text { fueron aclarando algunos recuerdos, descubriendo } \\
\text { que una tía se le había muerto su único hijo, después } \\
\text { de ese hecho entró en una etapa de depresión que } \\
\text { fue muy difícil sacarla de ese estado y al pasar los } \\
\text { años murió. } \\
\text {.....según información que obtuve de fuentes } \\
\text { escritas, uno de los hijos de mi tío } T \text {, no es realmente } \\
\text { suyo, aunque este no fue confirmado por el tío. } \\
\text {....descubrí que en realidad papi se casó dos veces y } \\
\text { yo creía que se había casado } 6 \text { veces: siempre se } \\
\text { habló de muchos matrimonios. } \\
\text {....pude conocer los problemas de pareja de mis } \\
\text { padres, sus frecuentes separaciones y la infidelidad } \\
\text { de mi papá. }\end{array}$ \\
\hline Dimensiones & Definición & Textos de las narraciones de los informantes \\
\hline Patrones que se repiten & $\begin{array}{l}\text { Conductas establecidas } \\
\text { en la familia que se } \\
\text { repiten de generación en } \\
\text { generación. }\end{array}$ & $\begin{array}{l}\text {.....mediante la construcción de mi genograma } \\
\text { descubrí que hay eventos que ocurrieron en mi } \\
\text { familia y que también se repiten en mi relación } \\
\text { familiar, hay triángulos que se repiten y no quiero que } \\
\text { esos triángulos se repitan en mis hijos. } \\
\text {.......pude ver que mi separación era como un patrón } \\
\text { seguido de la relación de mis padres, ellos terminaron } \\
\text { la relación de } \\
\text { pareja y siguieron viviendo en la misma casa, así pasó } \\
\text { con la mía. } \\
\text {......analizando todo, viendo y comparando, me di } \\
\text { cuenta que es cierto que mientras no conozcamos } \\
\text { nuestra historias podemos seguir los mismos } \\
\text { patrones de los padres. Mi hermano con sus hijos es } \\
\text { como mi papá, puro autoridad y castigo y nada de } \\
\text { afecto, no se comunica de forma asertiva. }\end{array}$ \\
\hline Asignación de roles & $\begin{array}{l}\text { Roles que son asignados } \\
\text { a miembros de la familia } \\
\text { sin acuerdos } \\
\text { conscientes. }\end{array}$ & $\begin{array}{l}\text {......ahora puedo confirmar que por la posición que } \\
\text { ocupo, de ser la hermana mayor siempre he sentido } \\
\text { que soy especial y que soy responsable de mantener } \\
\text { el bienestar de la familia o de continuar con la }\end{array}$ \\
\hline
\end{tabular}




\begin{tabular}{|c|c|c|}
\hline & & $\begin{array}{l}\text { tradición familiar y de cumplir con todas las } \\
\text { expectativas. } \\
\text {....con este trabajo tomé consciencia que en la familia } \\
\text { hay una clasificación entre hermanas, que han hecho } \\
\text { desde niñas como la buena y la mala que causó } \\
\text { heridas (en mi hermana), con respecto a esa situación } \\
\text { me gustaría que juntas no ayudarnos a liberar esa } \\
\text { carga que nos incomoda a ambas. }\end{array}$ \\
\hline Subcategoría & Definición & Textos de las narraciones de los informantes \\
\hline $\begin{array}{l}\text { Aceptación de } \\
\text { experiencias vividas }\end{array}$ & $\begin{array}{l}\text { Recibir las vivencias } \\
\text { familiares sin juicio. }\end{array}$ & $\begin{array}{l}\text {.....todo esto me ha llevado a cambiar el punto de } \\
\text { vista que tenia de los hechos ocurridos en mi familia, } \\
\text { ahora solo agradezco. } \\
\text {......trabajar con mi familia de origen ha sido una } \\
\text { experiencia que me ha llevado a recordar muchas } \\
\text { situaciones familiares vividas. Alguna veces siento la } \\
\text { necesidad de olvidar y recordar solo bueno que me } \\
\text { fortalece y me ayuda más que estar pensando en las } \\
\text { tristezas, descubrí que hay heridas que no han } \\
\text { sanado totalmente, pero que debo continuar } \\
\text { trabajando el perdón en mi vida. } \\
\text {......después de trabajar con mi familia puedo decir } \\
\text { que la aceptación de mi historia es primordial, ya que } \\
\text { mi pasado y las cosas que viví en mi hogar, ya no las } \\
\text { puedo cambiar y si sucedieron fue porque así estaba } \\
\text { dispuesto a ser. } \\
\text {.....hoy puedo decir que todas esas experiencias que } \\
\text { me han marcado durante mi vida la puedo recordar } \\
\text { como una enseñanza y olvidando el dolor que me } \\
\text { causaron en ese momento. }\end{array}$ \\
\hline Dimensiones & Definición & Textos de las narraciones de los informantes \\
\hline Cambio de conducta & $\begin{array}{l}\text { Forma diferente de } \\
\text { comportarse antes una } \\
\text { misma situación } \\
\text { familiar. }\end{array}$ & $\begin{array}{l}\text {.....siento que logré un cambio en la relación con mis } \\
\text { hermanos, creo que tengo que ser más tolerante para } \\
\text { tener una buena comunicación y que yo tengo que } \\
\text { dar el primer paso para que la relación cambie. } \\
\text {....puedo decir que ahora estoy valorando más a mi } \\
\text { mamá, y comprendiendo porque pelea tanto por su } \\
\text { casa pues le costó mucho obtenerla. } \\
\text {....luego de realizar este trabajo con mi familia de } \\
\text { origen me siento comprometida con ellos ya que al } \\
\text { conocer todas sus situaciones, sus problemas, me } \\
\text { gustaría ayudarlos y orientarlos, ya me he acercado } \\
\text { más a ellos sin juzgarlos. }\end{array}$ \\
\hline $\begin{array}{l}\text { Reconocimiento del valor } \\
\text { de la familia }\end{array}$ & $\begin{array}{l}\text { Apreciar y distinguir la } \\
\text { importancia que tiene la } \\
\text { familia, así como los } \\
\text { hechos vividos en ella. }\end{array}$ & $\begin{array}{l}\text {....recordar todos esos momentos vividos en mi } \\
\text { familia fue algo muy emocionante, ver que hay } \\
\text { tantos recuerdos de alegría y tristeza, y que siempre } \\
\text { estarán en nuestros corazones, hoy me siento } \\
\text { orgullosa de la familia que tengo y a la cual } \\
\text { pertenezco, y que ha dejado tanto momento } \\
\text { especiales en mi vida. }\end{array}$ \\
\hline
\end{tabular}




\begin{tabular}{|l|l|l|}
\hline & $\begin{array}{l}\text {...recordar todos esos momentos vividos en mi } \\
\text { familia fue algo muy emocionante, ver que hay } \\
\text { tantos recuerdos de alegría y tristeza, y que siempre } \\
\text { estarán en nuestros corazones, hoy me siento } \\
\text { orgullosa de la familia que tengo y a la cual } \\
\text { pertenezco, y que ha dejado tanto momento } \\
\text { especiales en mi vida. } \\
\ldots . \text { aunque estoy consciente que me ocurrieron } \\
\text { hechos dolorosos en mi infancia y adolescencia, } \\
\text { también puedo reconocer el gran amor que siento } \\
\text { por mi familia, indiferentemente del dolor que me } \\
\text { causaron esos hechos. }\end{array}$ \\
\hline
\end{tabular}

Estos datos obtenidos, permitieron comprender que el trabajo con la familia de origen, significa una vivencia transformadora de la historia familiar y personal, siendo definida como una experiencia que genera una nueva disposición a percibir y comprender su historia familiar y personal; igualmente se pudo determinar que el trabajo con la familia de origen, requiere de la búsqueda de información, lo que puede ocasionar, por un lado, resistencia a dar información, por parte de los familiares; pero igualmente puede presentarse la satisfacción por la oportunidad de compartir los acontecimientos requeridos.

También se evidenció que en el trabajo con la familia de origen, se presentan en los participantes, reacciones emocionales, tanto agradables, como desagradables. Otro hecho significativo que se vivió en el proceso, es el reconocimiento de acontecimientos develados, tales como la identificación de patrones que se repiten, así como roles asignados por el grupo familiar. Por último, se pudo vivenciar la aceptación de las experiencias vividas, a través de cambios de conductas y del reconocimiento del valor de la familia, indiferentemente, de los hechos ocurridos su la familia de origen.

Con respecto a los resultados de la revisión y discusión documental, se determinó que el trabajo con la familia de origen es un método de orientación e intervención, que facilita el desarrollo de habilidades personales y relacionales, a través del reconocimiento de la propia historia de la familia de origen; siendo empleado en las áreas de crecimiento personal, en terapia de pareja y como recurso en la formación del terapeuta/orientador familiar.

Igualmente, los antecedentes presentados en los trabajos realizados por Fombuena (2011), Carvajal (2012), Sandoval, Reducinco e Islas (2011), y Campo-Redondo (2004), permitieron determinar que las características personales del orientador/terapeuta, aprendidas en familia, influyen en su desempeño profesional, convirtiéndose en herramientas para el proceso de asesoría familiar; a la vez que se resalta la importancia de incluir el desarrollo de competencias personales y sociales en la formación del profesional de ayuda.

En cuanto a la revisión de reportes de actividades vivenciales que sustentan el trabajo personal del orientador, desde la historia familiar, presentados por Canevaro (2009), Maida, Molina y Albornoz (2003), Nitsche (2004) y Glasserman (2005), confirman que las historias familiares y personales pueden ser examinadas, transformadas y puestas al servicio del proceso de ayuda, durante la formación del orientador profesional, a través de diferentes métodos, técnicas e instrumentos, tales como: genograma, psicodrama, juegos de roles, convocatoria 
familia de origen, escultura familiar, relatos familiares, múltiples voces, uso de máscaras, entre otros.

Igualmente, se determina que las actividades vivenciales que sustentan el trabajo personal desde la historia familiar en el proceso de formación del orientador profesional, develan aportes en las áreas: familiar, personal y profesional. Además, la revisión y discusión teórica permitió definir la práctica de la orientación familiar como una disciplina científica, propuesta desde diferentes enfoques de asesoramiento e intervención; siendo considerada un proceso interactivo-vivencial, como toda relación humana; la cual transciende la perspectiva subjetiva, ubicándose en una dimensión intersubjetiva, que para Stolorow y Col (1987) puede entenderse como un método de entendimiento entre los participantes de la relación de ayuda (orientado/grupo familiar), y que para Campo-Redondo (2004), constituye la primera y primordial herramienta utilizada para fomentar el cambio; así como la principal fuente de conocimiento del caso asesorado.

Desde esta perspectiva, el orientador debe aprender a reconocer sus reacciones emocionales, cognitivas y conductuales, que de manera consciente e inconsciente, se presenta en la interacción con la familia atendida, y que pueden convertirse en recursos potenciales para la intervención, así como reacciones paralizantes y desorientadoras, como consecuencia de ciertas similitudes estructurales entre los sistemas familiares involucrados en el proceso de orientación familiar; siendo evidente la implicación personal en dicho proceso.

En cuanto a los referentes teóricos, que permitieron evidenciar la necesidad del trabajo personal en el orientador familiar, y que sustentan la importancia del trabajo con la familia de origen, fueron identificados los siguientes: la contratransferencia (Gorkin, 1987), el estilo de apego (Bowlby, 1989), el grado de diferenciación (Bowen, 1986), la cibernética de segundo orden (Von Foerster, 1990), la resonancia (Elkaim, 1989), el proceso de activación emocional (Chouhy, 2007) y las pautas de aprendizaje (Moles, 2004, Aponte 1994); los cuales exigen del orientador, la capacidad de auto-observación, la conciencia de su aporte al proceso, así como el reconocimiento de la complejidad humana.

Con respecto a los resultados de la fase de integración y teorización de los datos analizados, ésta se conformó a través de la integración de los datos obtenidos por cada tipo de unidad de análisis (informantes claves y datos documentales). Así entonces, se procedió a la formulación de categorías y subcategorías que fueron producto de la revisión, reconstrucción, saturación e interpretación de los hallazgos. El resultado del procedimiento ejecutado se presenta en la figura $\mathrm{N}^{\circ} 2$, donde se visualizan las dos categorías centrales y seis subcategorías develadas; además, se evidencia la interacción entre las categorías, de manera bidireccional; la relación entre las categorías y subcategorías y la conformación de un sistema de mutua interacción. Igualmente se presenta el cuadro No 2 dichas categoría y subcategorías junto con los ejemplos textuales según la unidad de análisis. 


\section{Figura $\mathrm{N}^{\circ} 2$}

Visualización de las categorías y subcategorías develadas en el proceso de integración de los hallazgos

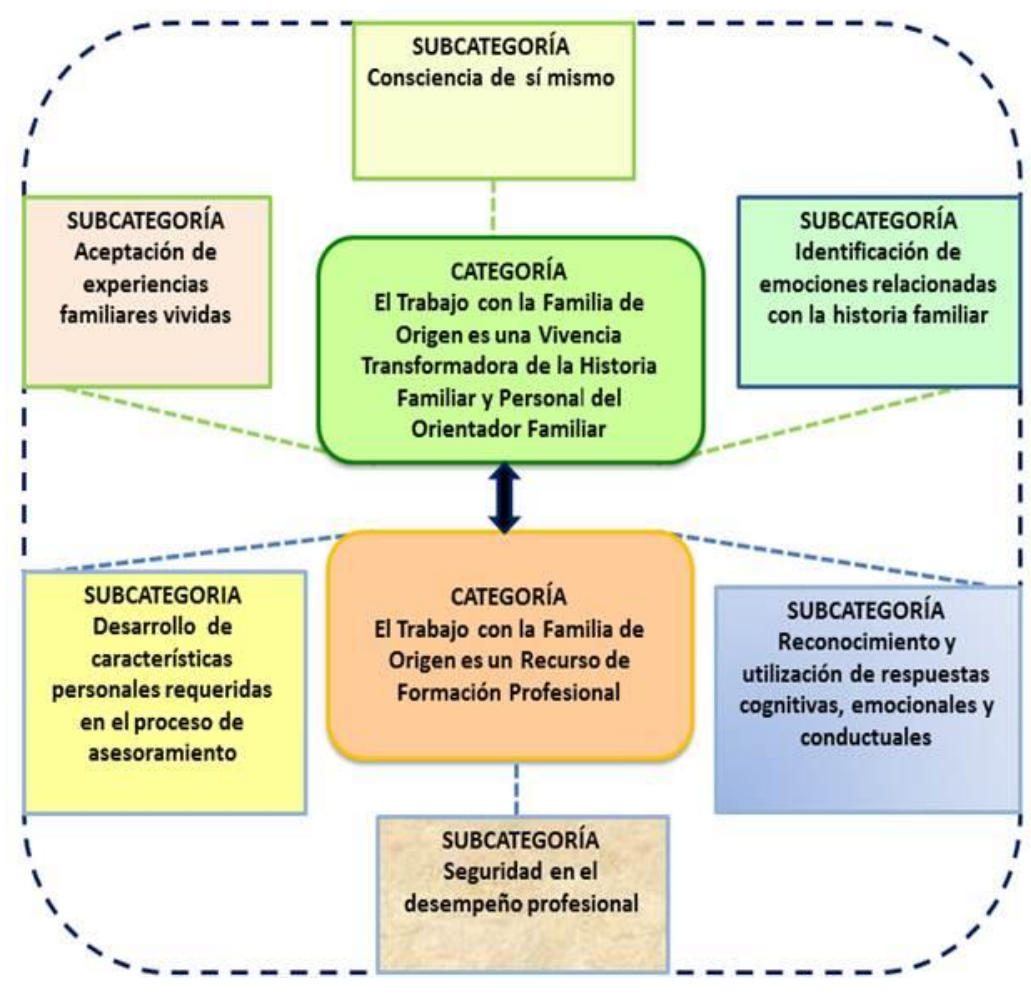

Cuadro $\mathrm{N}_{2} 2$

Presentación de categorías y subcategorías emergentes con sus respectivos ejemplos textuales por unidad de estudio

\begin{tabular}{|l|}
\hline Categoría \\
\hline Vivencia \\
Transformadora de \\
la Historia Familiar y \\
Personal del \\
Orientador Familiar \\
\end{tabular}

Informantes claves experiencias que me han marcado durante mi vida la puedo recordar como una enseñanza y olvidando el dolor que causaron en ese momento me ha permitido fortalecerme como persona para poder alcanzar las metas propuestas en la vida.

......he tomado consciencia de las situaciones pasadas que han afectado mi relación familiar. Ahora estoy consciente de lo que ha estado pasando en mi familia, que solo son programas que han venido dándose de generación en generación y debo cortar con eso. Ahora sé que lo que desconozco se

\section{Datos documentales}

....cuando el terapeuta/ orientador se apropia de su historia vivida y descubre nuevas configuraciones relacionales en su familia de origen, permite la reorganización de la percepción de sí mismo y su relación con los demás miembros de la familia, a la vez que se convierte en un parámetro de su desarrollo personal y profesional. (Chouhy 2007)

\section{CelR Vol. 11 (1) - Febrero 2017 ISSN 1988-2939-www.ceir.info}

() Derechos reservados/Copyright de Clínica e investigación Relacional y los autores. Prohibida la reproducción total o parcial sin autorización expresa. Este material es para uso científico y profesional exclusivamente y puede contener información clínica sensible. Los editores no se responsabilizan de los contenidos de los autores. Dirigir las consultas sobre derechos y autorizaciones a ceir@psicoterapiarelacional.es 


\begin{tabular}{|c|c|c|}
\hline & $\begin{array}{l}\text { puede repetiry lo que conozco yo decido } \\
\text { repetir o no. } \\
\text {......en este trabajo descubrí que a pesar } \\
\text { de las malas experiencias, también } \\
\text { tuvimos bellas experiencias. Que } \\
\text { muchas cosas dependen de nuestra } \\
\text { percepción de la situación, que no debo } \\
\text { enfocarme en lo que no tuve, sino más } \\
\text { bien en las cosas buenas de mis padres, } \\
\text { que si hago un balance fueron muchas, } \\
\text { que no tengo que arrastrar con mis } \\
\text { debilidades toda la vida, a cambio debo } \\
\text { enfocarme en lo bueno que puedo dar a } \\
\text { otros. }\end{array}$ & \\
\hline Subcategorías & Informantes claves & Datos documentales \\
\hline $\begin{array}{l}\text { Aceptación de } \\
\text { experiencias } \\
\text { familiares vividas }\end{array}$ & $\begin{array}{l}\text {.....todo esto me ha llevado a cambiar el } \\
\text { punto de vista que tenia de los hechos } \\
\text { ocurridos en mi familia, ahora solo } \\
\text { agradezco. } \\
\text {.....trabajar con mi familia de origen ha } \\
\text { sido una experiencia que me ha llevado a } \\
\text { recordar muchas situaciones familiares } \\
\text { vividas. Alguna veces siento la necesidad } \\
\text { de olvidar y recordar solo bueno que me } \\
\text { fortalece y me ayuda más que estar } \\
\text { pensando en las tristezas, descubrí que } \\
\text { hay heridas que no han sanado } \\
\text { totalmente, pero que debo continuar } \\
\text { trabajando el perdón en mi vida. } \\
\text {......después de trabajar con mi familia } \\
\text { puedo decir que la aceptación de mi } \\
\text { historia es primordial, ya que mi pasado } \\
\text { y las cosas que viví en mi hogar, ya no las } \\
\text { puedo cambiar y si sucedieron fue } \\
\text { porque así estaba dispuesto a ser. }\end{array}$ & $\begin{array}{l}\text {....las historias personales pueden ser } \\
\text { examinadas, aceptadas, transformadas } \\
\text { y puestas al servicio del proceso de } \\
\text { ayuda, durante la formación del } \\
\text { orientador profesional. (Glasserman } \\
\text { 2005) }\end{array}$ \\
\hline $\begin{array}{l}\text { Identificación de } \\
\text { emociones } \\
\text { relacionadas con la } \\
\text { historia familiares }\end{array}$ & $\begin{array}{l}\text {.....pude comprender la emoción de } \\
\text { dolor que está detrás del rompimiento } \\
\text { de la relación de pareja en mi familia; mis } \\
\text { padres se separaron, después de una } \\
\text { larga relación conflictiva; hoy vivo una } \\
\text { situación muy parecida y siento el mismo } \\
\text { dolor que de niña. En mi familia el } \\
\text { matrimonio es para toda la vida, aunque } \\
\text { ya no exista el amor. } \\
\text {.....descubrí hay una emoción de } \\
\text { frustración en la relación con mi padre, } \\
\text { fue muy autoritario, no quisiera } \\
\text { repetirlo. }\end{array}$ & $\begin{array}{l}\text {.... destaca la importancia del trabajo } \\
\text { con la historia de la familia del } \\
\text { orientador/terapeuta familiar, } \\
\text { argumentando que esto evitaría las } \\
\text { reacciones emocionales no conscientes } \\
\text { del orientador (rabia, angustia, otros) } \\
\text { que podría desorientarlo o paralizarlo, } \\
\text { como consecuencia de la presencia de } \\
\text { ciertas similitudes estructurales o } \\
\text { isomorfismos, entre los sistemas } \\
\text { familiares del orientador y el de la } \\
\text { familia que asesora. (Chouhy 20o7) } \\
\text {.....el concepto de resonancia es } \\
\text { efectivo sólo si el orientador ha } \\
\text { aprendido a utilizar las emociones o }\end{array}$ \\
\hline
\end{tabular}

\section{CelR Vol. 11 (1) - Febrero 2017 ISSN 1988-2939-www.ceir.info}

@ ( Derechos reservados/Copyright de Clínica e investigación Relacional y los autores. Prohibida la reproducción total o parcial sin autorización expresa. Este material es para uso científico y profesional exclusivamente y puede contener información clínica sensible. Los editores no se responsabilizan de los contenidos de los autores. Dirigir las consultas sobre derechos y autorizaciones a ceir@psicoterapiarelacional.es 


\begin{tabular}{|c|c|c|}
\hline & & $\begin{array}{l}\text { percepciones que el sistema } \\
\text { terapéutico evoca y/o amplifica de su } \\
\text { propia historia familiar, en modo tal de } \\
\text { evitar que las construcciones del mundo } \\
\text { de todos los miembros del sistema se } \\
\text { refuercen mutuamente. (Elkaim 1989) }\end{array}$ \\
\hline $\begin{array}{l}\text { Consciencia de sí } \\
\text { mismo }\end{array}$ & $\begin{array}{l}\text {.....hoy me siento más segura de mi } \\
\text { misma, se que soy mi historia familiar (lo } \\
\text { agradable y desagradable), ahora me } \\
\text { conozco más. }\end{array}$ & $\begin{array}{l}\text {.....el crecimiento personal del } \\
\text { profesional, así como el desarrollo de la } \\
\text { conciencia sobre sí mismo, se erigen } \\
\text { como pilares básicos para su evolución } \\
\text { en el desempeño de su labor. (Safrán y } \\
\text { Muran 2005) } \\
\text {....pone el acento en la necesidad del } \\
\text { trabajo con la familiar de origen en la } \\
\text { formación del terapeuta familiar, } \\
\text { reconociendo que la diferenciación del } \\
\text { sí mismo es necesaria no sólo para el } \\
\text { crecimiento personal, sino también } \\
\text { para lograr un mejor desarrollo } \\
\text { profesional. (Bowen 1991) }\end{array}$ \\
\hline Categoría & Informantes claves & Datos documentales \\
\hline $\begin{array}{l}\text { Recurso de } \\
\text { Formación } \\
\text { Profesional }\end{array}$ & $\begin{array}{l}\text {.....en el trabajo con la historia de mi } \\
\text { familia de origen entendí que es una gran } \\
\text { herramienta para mi formación, además } \\
\text { de una estrategia de acompañamiento o } \\
\text { terapia familiar y personal. }\end{array}$ & $\begin{array}{l}\text {.....el ejercicio de la revisión de la propia } \\
\text { historia familiar, en el contexto de } \\
\text { formación, a través del trabajo } \\
\text { experiencial, se reporta como un } \\
\text { aprendizaje de destrezas en el campo } \\
\text { profesional y al mismo tiempo como } \\
\text { una experiencia transformadora de la } \\
\text { vida personal. (Maida, Molina, y } \\
\text { Albornoz (2003) } \\
\text {.....resalta la importancia del trabajo } \\
\text { personal, a través, de técnicas como la } \\
\text { escritura de cuentos, relatos, } \\
\text { construcción de genograma familiar en } \\
\text { la formación del profesional de ayuda. } \\
\text { (Nitsche 2004) }\end{array}$ \\
\hline Subcategorías & Informantes claves & Datos documentales \\
\hline $\begin{array}{l}\text { Desarrollo de } \\
\text { características } \\
\text { personales } \\
\text { requeridas en el } \\
\text { proceso de } \\
\text { asesoramiento }\end{array}$ & $\begin{array}{l}\text {...esto me ha permitido fortalecerme } \\
\text { como persona, me siento más segura de } \\
\text { mí. }\end{array}$ & $\begin{array}{l}\text {.....los recursos personales, aprendidos } \\
\text { en familia, forman parte de la batería de } \\
\text { competencias y habilidades necesarias } \\
\text { para la intervención y estos pueden ser } \\
\text { fortalecidos a través del } \\
\text { reconocimiento de su historia familiar. } \\
\text { (Fombuena 2011) } \\
\text {.....el impacto de las experiencias } \\
\text { personales, desde muy temprana edad, } \\
\text { ejerce una influencia notoria en ellos } \\
\text { (terapeuta orientador) y en el trabajo } \\
\text { que realizan. El profesional hace terapia } \\
\text { con lo que es, es decir, el resultado de la }\end{array}$ \\
\hline
\end{tabular}

\section{CelR Vol. 11 (1) - Febrero 2017 ISSN 1988-2939 - www.ceir.info}

@ ( Derechos reservados/Copyright de Clínica e investigación Relacional y los autores. Prohibida la reproducción total o parcial sin autorización expresa. Este material es para uso científico y profesional exclusivamente y puede contener información clínica sensible. Los editores no se responsabilizan de los contenidos de los autores. Dirigir las consultas sobre derechos y autorizaciones a ceir@psicoterapiarelacional.es 


\begin{tabular}{|c|c|c|}
\hline & & $\begin{array}{l}\text { experiencia vivida acumulada y la } \\
\text { formación recibida.(Carvajal 2012) }\end{array}$ \\
\hline $\begin{array}{l}\text { Reconocimiento y } \\
\text { utilización de } \\
\text { respuestas } \\
\text { cognitivas, } \\
\text { emocionales y } \\
\text { conductuales }\end{array}$ & $\begin{array}{l}\text {.....con este trabajo sentí muchas } \\
\text { emociones, pensé mucho, pero } \\
\text { continué; creo que debo continuar } \\
\text { aprendiendo; también pude reconocer } \\
\text { las emociones de mis compañeros } \\
\text { cuando exponían sus genogramas. }\end{array}$ & $\begin{array}{l}\text {.....el orientador familiar debe estar } \\
\text { capacitado para volverse sensible a la } \\
\text { percepción de sus propias señales } \\
\text { emocionales y conductuales que lo } \\
\text { alertan acerca de si él, está manejando } \\
\text { o no satisfactoriamente los aspectos } \\
\text { personales de su relación con familia } \\
\text { atendida. Aponte (1985) } \\
\text {....el proceso de orientación familiar, } \\
\text { no está solamente determinada por la } \\
\text { historia del orientado, sino que también } \\
\text { está presente la historia del } \\
\text { terapeuta/orientador, quien deberá ser } \\
\text { consciente de su propia contribución a } \\
\text { la relación para poder actur } \\
\text { construyendo un vínculo de apego } \\
\text { seguro. (Bowlby 1989) }\end{array}$ \\
\hline $\begin{array}{l}\text { Seguridad en el } \\
\text { desempeño } \\
\text { profesional }\end{array}$ & $\begin{array}{l}\text {.....en lo personal me ayudó a ver que esa } \\
\text { es mi familia a la que quiero y amo... } \\
\text { También en lo profesional me ayuda a } \\
\text { conocer otra técnica con la cual trabajar } \\
\text { los casos familiares y personales que } \\
\text { llevo en mi lugar de trabajo, lo que } \\
\text { enriquece mi desempeño como } \\
\text { orientadora. }\end{array}$ & $\begin{array}{l}\text {.....se vincula las narrativas que tienen } \\
\text { los entrenados (orientadores y } \\
\text { terapeuta de parejas y familias) acerca } \\
\text { de sus familias de origen, con algunos } \\
\text { obstáculos que se les presentan en su } \\
\text { desempeño profesional, que en ciertos } \\
\text { momentos pueden vincularse a "puntos } \\
\text { ciegos" de su historia familiar; y se } \\
\text { propone el reconocimiento de dichas } \\
\text { situaciones en beneficio de su } \\
\text { desempeño profesional. (Glasserman } \\
2005 \text { ) } \\
\text {....ningún terapeuta/orientador puede } \\
\text { ayudar una persona o grupo familiar en } \\
\text { la diferenciación de su familia, más allá } \\
\text { del grado de diferenciación alcanzado } \\
\text { por el mismo en su propia familia de } \\
\text { origen. (Bowen 1991) }\end{array}$ \\
\hline
\end{tabular}

A partir de los resultados obtenidos se procedió a la construcción del esquema teórico-explicativo de la incidencia del trabajo con la familia de origen del orientador en la práctica de la orientación familia. En el proceso se unen las dos categorías centrales develadas (Experiencia vivencial y transformadora de la historia familiar y Recurso de formación); se integran las subcategorías referidas a las competencias personales (Aceptación de experiencias familiares vividas, identificación de emociones relacionadas con la historia familiar; reconocimiento y utilización de respuestas cognitivas, emocionales y conductuales); quedando las subcategorías seguridad en el desempeño profesional y consciencia de sí mismo como fueron presentadas. Todo lo señalado, conforman un sistema de mutua influencia, que activa un recurso significativo que incide en el fortalecimiento de la práctica de la orientación familiar. Dicho esquema se visualiza en la figura 3. expresa. Este material es para uso científico y profesional exclusivamente y puede contener información clínica sensible. Los editores no se responsabilizan de los contenidos de los autores. Dirigir las consultas sobre derechos y autorizaciones a ceir@psicoterapiarelacional.es 
Figura $\mathrm{N}^{\circ} 3$

Visualización del esquema teórico-explicativo sobre la incidencia del trabajo con la familia de origen del orientador en la práctica de la orientación familiar

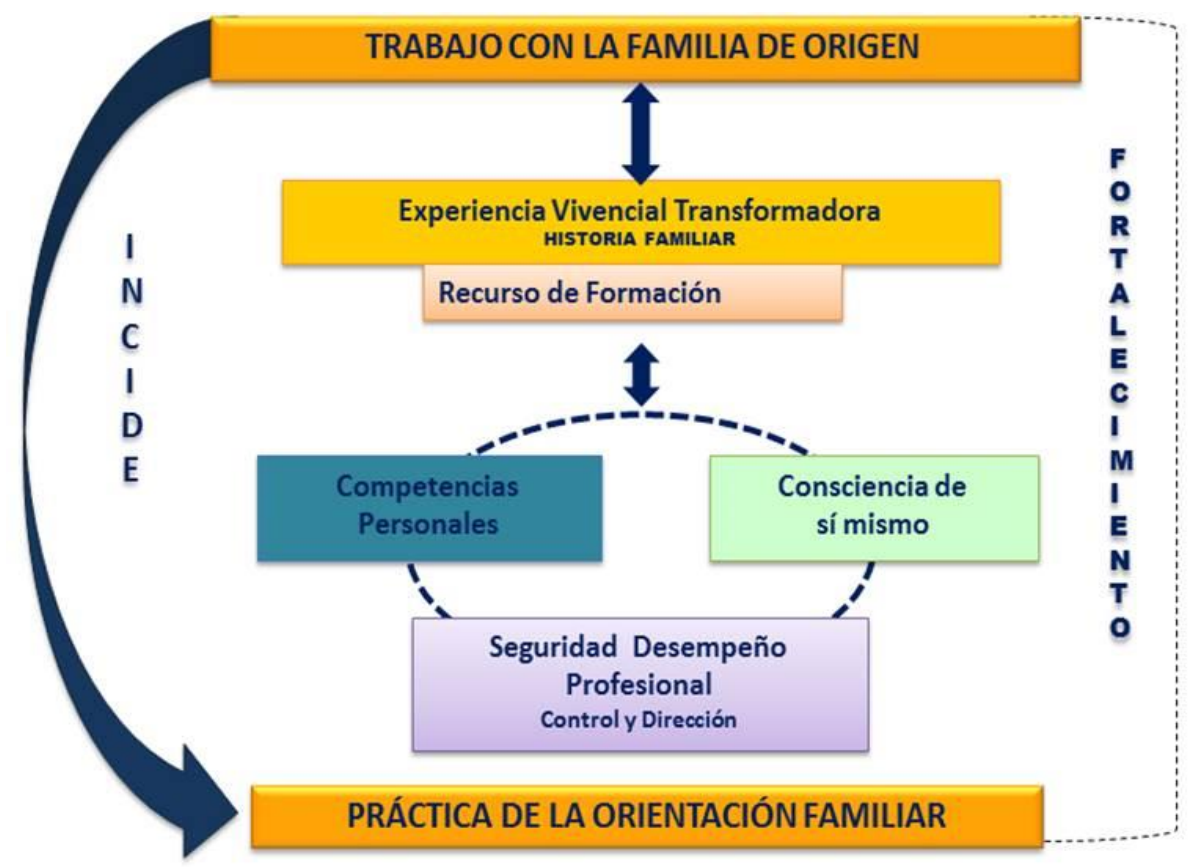

Desde el esquema presentado se establece como aproximación teórica que el trabajo con la familia de origen, es una vivencia transformadora, que genera una nueva disposición a percibir y comprender su propia historia familiar, siendo considerado una vía para el encuentro y revisión de situaciones vividas en familia; así como, un recurso de formación del orientador familiar, que facilita el desarrollo de competencias personales, la búsqueda de la consciencia de sí mismo y seguridad en el desempeño profesional, desde el control y dirección del proceso de asesoramiento; lo que lleva a la afirmación que el trabajo con la familia de origen incide en el fortalecimiento de la práctica de la orientación familiar.

\section{CONSIDERACIONES FINALES}

La orientación familiar como disciplina especializada, con un alto nivel de complejidad y de exigencia profesional, requiere del dominio de competencias profesionales, tanto personales, como relacionales, sustentada en una visión sistémica, indiferentemente del modelo teórico que fundamente su formación. Además, la práctica de la orientación familiar es un proceso interactivo, vivencial e intersubjetivo, que lleva al orientador, a la activación (consciente e inconsciente) de reacciones cognitivas emocionales y conductuales; quien debe aprender a identificar y utilizar como recurso significado en el proceso de asesoramiento.

Por otro lado, el orientador tiene una historia familiar, cargada de hechos significativos, que influye, en menor o mayor grado, en la percepción de las situaciones familiares vivenciadas en el presente, específicamente, las relacionadas con las historias de los casos atendidos; lo que puede 
llevar al orientador, a fusionar sus vivencias familiares, con las de las familias atendidas; como consecuencia de habilidades no desarrolladas.

Las consideraciones señaladas, advierte la importancia del desarrollo profesional del orientador familiar, más allá, de un dominio teórico; su formación requiere del reconocimiento de la autorefencia como fuente epistemológica en el asesoramiento familiar, lo que implica generar instancia que promueva procesos de autobservación y revisión de referentes propios. De allí, que el trabajo con la familia de origen se presenta como una oportunidad para el encuentro con la vivencias familiar, que consciente o no, han dejado huellas y están presente en el actuar y sentir como orientador.

En ese sentido, cabe destacar que el genograma familiar es una estrategia estructura, sistémica, de impacto emocional y motivacional, que permite la identificación, visualización y reflexión de la historia familiar. Además, en la presente investigación, se logró determinar que el trabajo con la familia de origen, a través de autoconstrucción del genograma familiar, es una estrategia viable a utilizar en el contexto de formación del orientador familiar.

En cuanto al resultado final de la investigación, se establece como aproximación teórica que el trabajo con la familia de origen, es una vivencia transformadora, que genera una nueva disposición a percibir y comprender su propia historia familiar, siendo considerado una vía para el encuentro y revisión de situaciones vividas en familia; así como, un recurso de formación del orientador familiar, que facilita el desarrollo de competencias personales, la búsqueda de la consciencia de sí mismo y seguridad en el desempeño profesional, desde el control y dirección del proceso de asesoramiento; lo que lleva a la afirmación que el trabajo con la familia de origen incide en el fortalecimiento de la práctica de la orientación familiar.

Para la investigación, la incidencia develada, se declara como la posibilidad de un desarrollo profesional, dirigido al reconocimiento de la persona como recurso en el proceso de asesoramiento, y donde la reflexión de las vivencias familiares, se consolide como una opción en la formación del orientador familiar.

De igual modo, cabe señalar que la práctica de la orientación familiar es conducida por personas y el cambio en el proceso de asesoramiento se da a través de una relación de mutua influencia, entre el orientador y los orientados; lo que implica, para el orientador, el reconocimiento de la consciencia de sí mismo; así como seguridad en el control y dirección del proceso, desde una perspectiva sistémica.

\section{REFERENCIAS}

Ainsworth,M. (1989). Attachaments Beyong Infancy. American Psychologist, New Books.

Aponte, R. (1994). Del Pensamiento al Placer. Editorial Planeta.

Becker, H. (1970). Sociological Work: method and sabstance, New Brunswick: Transacton.

Bowen, M. (1986). Family therapy in clinical practice.USA. JasonJonson.

Bowen, M. (1991). De la familia al individuo. La diferenciación del sí mismo en el sistema familiar. Barcelona, Ediciones Paidos.

Bowlby, J. (1989). Una Base Segura: Aplicaciones Clínicas de una Teoría del Apego. Buenos Aires: Paidós. 
Campo-Redondo, M. (2004). Intersubjetividad en la Orientación de la Violencia Familiar. Tesis Doctoral. Universidad del Zulia. Venezuela.

Canevaro, A. (2009). El Trabajo Directo con las Familias de Origen de los Terapeutas en Formación. Apuntes de Psicologia, Vol. 27, número 2-3, Colegio Oficial de Andalucía Occidental, España.

Chouhy, A. (2007). Parámetros de Desarrollo en la Formación del Terapeuta Familiar: El Proceso de Apropiación de la Historia Familiar del Terapeuta. Redes: Revista de psicoterapia relacional e intervenciones sociales. ISSN 1135-8793, $\mathrm{N}^{\circ} 18$.

Elkaim, M. (1984). Si me Amas, no me Ames, Ed: gedisa.

Fombuena, j. (2011). Un Estudio de las Familias de Origen de los y las Trabajadoras Sociales desde el Modelo Contextual. Comunitaria, Revista Internacional de Trabajo Social y Ciencias Sociales. Valencia

Glasserman, M. (2005). Sintesis del taller vivencial realizado por la Lic. M. Rosa Glasserman en el IV Congreso Mundial de Psicoterapia 2005. Dispb:http://familiasyparejas.com.ar/genograma-lic-m-rosaglasserman. Consulta: 04-12-14.

González, C. (2006). La Persona del Terapeuta Familiar. Universidad de Olavide. Sevilla, España. Ponencia. Gorkin, M. (1987).The Uses of Countertransference. Aronson, Northvale, Nuw Jersey.

Guy, J. (1995). La Vida Personal del Psicoterapeuta. El impacto de la práctica clínica en las emociones y vivencias del terapeuta. EdicionesPaidos. España.

Hage, J. (1972). Techniques and problems of theory construction in sociology. Nueva York: John Wiley.

Henry, W. Sims, J. Y Spray, S. (1973). Public and Pricate lives of Psychotherapists. San Francisco: JosseyBass.

Kerr.M. y bowen, m. (1988). Family Evaluation: An Approach Based om Bowen Theory. New York, Ny: w.w. Norton \& Company.

Mcgoldrick, M. y Gerson, R. (1987).Genograma en la Evaluación Familiar. Gedina editorial. Buenos Aires. LEDOUX, J. (2005). Le Cerveau des Emotions. EditionsOdile Jacob.

Maida, A., Molina, M. y Albornoz. M. (2003). Taller "La persona del terapeuta": Una experiencia de formación que promueve el aprendizaje. Revista: Educación Médica, 6(2). 112-116; 11 ref. ISSN: 1575-1813.

Mahoney, M. (1991). Human Change Processes. New York: Basic Books.

Moles, J. (2004). Psicología Conductual. Impreso por Grafi Aragua, S.R.L., Maracay - Venezuela.

Naiper, A y Whitaker, C. (1982). El Crisol de la Familia. AmorrortuEditores. Buenos Aires, Argentina.

Nicolescu, B (1999). La Transdisciplinariedad, una nueva visión del mundo. (Documento en línea). Disponible: http//perso.club-internet.fr/nicol/ciret. (Consulta: 2016, Febrero 17).

Nitsche, R. (2004). Exploración del Rol de Terapeutas: Psicodrama y Máscaras. Taller de Formación para Terapeutas. Revista de familias y Terapias. Año 12, $N^{\circ} 19$. Chile.

Núñez, A. y Tobón, S. (2005). Terapia Cognitivo-Conductual. El modelo procesual de la salud mental como camino para la integración, la investigación y la clínica. Editorial Universidad de Manizales.MadridEspaña. 
Kerr, M Y Bowen. (1988). Family Evaluation: An approach based on Bowen Theory. Neww, NY: W.W. Norton \&Company.

Kerr, M. (1984). Theoretical base of differentiation of self in ones's family of origin. New York, The Haworth.

Safrán, J. y Muran, Ch. (2005). La Alianza Terapéutica. Ed. Desclée de Browwer. Bilbao. España.

Salem, G. (1990). Abordaje Terapéutico de la Familia. Masson. Barcelona.

Sandoval, L., Reducindo, R. e Islas, A. (2011). Funcionamiento Familiar y Empatía en los Médicos Residentes del Instituto de Seguridad y Servicios Sociales de los Trabajadores del Estado. Revista de Especialidades Médico-Quirúrgicas. Volumen 16, Número 4.octubre- diciembre.

Straus, A. Y Corbin, I. (2002). Bases de la Investigación Cualitativa. Tècnicas y Procedimientos para desarrollar la Teoría Fundamentada. Editorial Universidad de Antioquia, Colombia.

Stolorow, R. y Col. (1987). Psychoanalytic Treatment: An Intersubjective Approach. The AnalyticPress. Hillsdale, NJ.

Von Foerster, H. (1990). Ethics and Secondorder Cybernetics.Systems and Family Therapy. International Conference.

Original recibido con fecha: $\quad$ 5-1-2017 $\quad$ Revisado $\quad$ 28-2-2017 $\quad$ Aceptado 28-2-2017 